\title{
Major Dietary Patterns in Relation to Stunting among Children in Tehran, Iran
}

\author{
Fatemeh Esfarjani', Roshanak Roustaee', \\ Fatemeh Mohammadi-Nasrabadi', Ahmad Esmaillzadeh ${ }^{2,3}$ \\ 'Department of Food Policy and Nutrition Planning, National Nutrition and Food Technology Research Institute, \\ Faculty of Nutrition Sciences and Food Technology, Shahid Beheshti University of Medical Sciences, Tehran, Iran; \\ ${ }^{2}$ Food Security Research Center, ${ }^{3}$ Department of Community Nutrition, School of Nutrition and Food Science, \\ Isfahan University of Medical Sciences, Isfahan, Iran
}

\begin{abstract}
To the best of our knowledge, no information is available to link major dietary patterns to stunting during childhood, although dietary patterns are associated with chronic diseases. This study was conducted to determine the relationship between major dietary patterns and stunting in the first grade pupils of Tehran in 2009. In this case-control study, 86 stunted children (defined as height-for-age of less than the 5th percentile of CDC2000 cutoff points) were enrolled from among 3,147 first grade pupils of Tehran, selected using a multistage cluster random-sampling method. Participants for the control group $(n=308)$ were selected randomly from non-stunted children (height-for-age more than the 5th percentile of CDC2000 cutoff points), after matching for age, sex, and area of residence. Dietary data were collected using two 24hour dietary recalls through face-to-face interview with mothers. Factor analysis was used for identifying major dietary patterns. Mean consumption of dairy products ( $308 \pm 167$ vs $382 \pm 232 \mathrm{~g} / \mathrm{day}$, $\mathrm{p}<0.05$ ), dried fruits and nuts $(2.58 \pm 9$ vs $7.15 \pm 26 \mathrm{~g} / \mathrm{day}, \mathrm{p}<0.05)$ were significantly lower among stunted children than those in the control group. Three major dietary patterns were identified: 'traditional dietary pattern' that was dominated by bread, potato, fats, eggs, flavours, vegetables other than leafy ones, sugar, drinks, and fast food; 'mixed dietary pattern' that was dominated by leafy vegetables, fast foods, nuts, fats, cereals other than bread, fruits, legumes, visceral meats, sugars, eggs, and vegetables other than leafy vegetables; and 'carbohydrate-protein pattern' that was dominated by sweets and desserts, poultry, dairy, fruits, legumes, and visceral meats. No significant relationships were found between traditional and mixed dietary patterns and stunting. Individuals in the third quartile of carbohydrate-protein dietary pattern were less likely to be stunted compared to those in the bottom quartile (OR: 0.31, 95\% CI 0.13-0.78, p<0.05). Adherence to dietary patterns high in protein (e.g. dairy, legumes, and meat products) and carbohydrates (e.g. fruits, sweets, and desserts) might be associated with reduced odds of being stunted among children.
\end{abstract}

Key words: Child; Dietary pattern; Factor analysis; Stunting; Iran

\section{INTRODUCTION}

Stunting, defined as "the gaining of insufficient height relative to age" (1) during childhood is a major public-health problem in underdeveloped and developing countries (1-4). The 2000 report of

Correspondence and reprint requests:

Dr. Ahmad Esmaillzadeh

Department of Community Nutrition

School of Nutrition and Food Science

Isfahan University of Medical Sciences

PO Box 81745-151

Isfahan

Iran

Email: esmaillzadeh@hlth.mui.ac.ir

Fax: +98-311-6682509 the World Health Organization (WHO) stated that 215 million children were stunted. Findings from a national survey in Iran in 2005 indicated that $4.7 \%$ of Iranian children were affected (5). Stunting in children is associated with current, and possibly later, delayed mental and motor development (67). Limited work-capacity due to reduced muscle mass has also been reported among stunted people (6). Earlier studies have also found increased obstetric risks among stunted women (8).

Linear growth retardation, which is the manifestation of chronic malnutrition, can be developed from inadequate intake of food, inappropriate quality of diet, or a combination of both (6-10). Numer- 
ous studies that have been conducted on growthlimiting nutrients have indicated that primary deficiency of zinc, vitamin A, and iron, along with insufficient intake of protein and energy, might result in stunting $(5,11-14)$. However, it must be kept in mind that interactions between nutrients might confound the association of a specific nutrient with stunting. To overcome these problems, nutritional epidemiologists have suggested the use of a dietary pattern approach as a new direction in nutritional epidemiology to find diet-disease relationships (14). Using a multivariate approach could control potential dietary confounders and food and nutrient interactions (15-17).

Generally, several studies have assessed dietary patterns in relation to numerous outcomes. Most of these studies have been performed among adults in western societies; limited information is available about major dietary patterns of children worldwide, particularly in region of the Middle East not studied well. Furthermore, although the association of several nutrients with stunting has received great attention, we are unaware of any studies linking major dietary patterns to stunting, particularly among children $(12-14,18)$. This study was, therefore, conducted to determine the relationship between major dietary patterns and stunting in the first grade pupils of Tehran, Iran.

\section{MATERIALS AND METHODS}

\section{Subjects}

This case-control study has been done in the framework of a cross-sectional survey that was performed among 3,147 first grade pupils aged 7 years, who were selected using a multistage cluster randomsampling method from 42 elementary schools in 5 districts of Tehran (northern, southern, eastern, western, and central part of Tehran). Children's weight was measured while the subjects were minimally clothed without shoes, using digital scales and recorded to the nearest $100 \mathrm{~g}$. Height was measured in a standing position, without shoes, using tapemeter while shoulders were in a normal state. Body mass index was calculated as weight in kilogramme divided by height in metres squared. To avoid subjective error, all measurements were taken by the same person. Stunting was defined as height-for-age of less than the 5th percentile of the Center for Disease Control and Prevention 2000 (CDC2000) cutoff points. Qualified children $(\mathrm{N}=117)$, whose parents agreed to participate in the study, were specified as a case group $(n=86)$. After matching for age, sex, and area of residence, we se- lected 3 apparently healthy non-stunted children [(height-for-age equal to and more than the 5th percentile of CDC2000 cutoff points for each stunted kid as their controls $(n=308)]$. Therefore, in the current study, we examined 394 students in total.

The Ethics Committee of the National Nutrition and Food Technology Research Institute approved this study, and informed written consent was obtained from all participants and their parents.

\section{Assessment of dietary intake}

Dietary intakes of the study participants were assessed by means of two quantitative non-consecutive 24-hour dietary recalls (one for a weekday and the other for a weekend). Subjects were usually interviewed, along with their parents by a face-toface method. The subjects and their parents were asked to recall all foods and beverages they consumed during the preceding 24-hours. To assist subjects and their parents to recall accurately, household utensils were used. Portion-sizes of consumed foods were converted to gramme, using household measures. Each food and beverage was then coded according to prescribed protocol and analyzed for contents of energy and other nutrients, using Nutritionist-III (N3) Software program designed for Iranian foods. Almost all foods eaten by our subjects could be coded. When a particular ethnic food was not in the database of N3, we coded it as a similar item.

\section{Assessment of other variables}

Required information on demographic characteristics and socioeconomic status (householdsize, parity, parent's job, education, marital status, mother's age, and home ownership), birthweight and height, and duration of breastfeeding was obtained for each subject through interviewing their mothers.

\section{Statistical analysis}

We used factor analysis to identify major dietary patterns. First, due to the large number of food items relative to the number of participants, we assigned each food-item into 22 predefined food groups (Table 1), based on the similarity in their nutrient contents. Principal component analysis was done with the factors rotated by orthogonal transformation. The natural interpretation of the factors in conjunction with eigenvalues $(\geq 1.3)$ and Scree plot determined whether a factor should be retained. The derived factors (dietary patterns) were labelled on the basis of our interpretation of 


\begin{tabular}{|c|c|}
\hline Food group & Food item \\
\hline Bread & $\begin{array}{l}\text { Dark breads (Iranian), barley bread, bulgur, white breads (lavash, baguettes), } \\
\text { toasted bread, sweet bread }\end{array}$ \\
\hline Other cereals & White flour, noodles, pasta, rice, popcorn, cornflakes \\
\hline Legumes & Beans, peas, lima beans, broad beans, lentils, soy \\
\hline Potato & Potatoes, French fries, potato chips \\
\hline Leafy vegetables & Spinach, lettuce, mixed vegetables \\
\hline Other vegetables & $\begin{array}{l}\text { Carrots, cabbage, cauliflower, kale, tomatoes, cucumber, eggplant, celery, green } \\
\text { peas, green beans, green pepper, turnip, corn, squash, mushrooms, onions, garlic, } \\
\text { okra, beats }\end{array}$ \\
\hline Fruits & $\begin{array}{l}\text { Fruit pears, apricots, cherries, apples, raisins or grapes, bananas, cantaloupe, wa- } \\
\text { termelon, oranges, grapefruit, kiwi, strawberries, peaches, nectarine, tangerine, } \\
\text { mulberry, plums, persimmons, pomegranates, lemons, pineapples, figs and dates, } \\
\text { apple juice, orange juice }\end{array}$ \\
\hline Red meats & Beef, lamb, hamburger \\
\hline Poultry & Chicken with or without skin \\
\hline Fish & Canned tuna fish, other fish \\
\hline Visceral meats & Beef liver \\
\hline Eggs & Eggs \\
\hline Dairy products & $\begin{array}{l}\text { Milk (skimmed or low-fat/high-fat, whole); chocolate milk, yogurt (low-fat/high- } \\
\text { fat/cream); yogurt drink (doogh), cream cheese, other cheeses, ice cream }\end{array}$ \\
\hline Fat and oil & $\begin{array}{l}\text { Butter, margarine, olive, olive oils, hydrogenated fats, animal fats, vegetable oils, } \\
\text { mayonnaise, cream }\end{array}$ \\
\hline Sugars & $\begin{array}{l}\text { Sugars, candies, gaz (an Iranian confectionery item made of sugar, nuts, and tama- } \\
\text { risk), condiments jam, jelly, honey }\end{array}$ \\
\hline Sweets and desserts & Biscuits, cakes, cookies, chocolates \\
\hline Nuts & Peanuts, almonds, pistachios, hazelnuts, roasted seeds, walnuts \\
\hline Dried fruits & Dried figs, dried mulberries, other dried fruits, raisins \\
\hline Drinks & Tea, coffee, soft drinks, synthetic fruit juice \\
\hline Flavours & Tomato sauce, tomato pasta, pickles, vinegar, salty cucumber, pomegranate paste \\
\hline Fast food & Sausages, salami, bologna, pizza, kebab, lasagna \\
\hline Others & Gum, crackers \\
\hline
\end{tabular}

data and on prior literature. The factor score for each pattern was calculated by summing intakes of food groups weighted by their factor loadings, and each participant received a factor score for each identified pattern.

Participants were categorized based on quartiles of dietary pattern scores. To determine the association of dietary patterns with stunting, we used multivariate logistic regression. Regression analysis was controlled for their age, sex, parent's age and education, birthweight, family-size, duration of breastfeeding, and total energy intake in different models. The first quartile of dietary pattern scores was reconsidered a reference in each model. All statistical analyses were done by Statistical Package for Social Sciences software (SPSS Inc, version 16).

\section{RESULTS}

For the whole population $(n=3,147)$ in the crosssectional survey, the prevalence of stunting was $3.7 \%$-significantly higher in girls than that in boys (4.4\% vs $2.8 \%$, p<0.05). Also, the mean birthweight was significantly lower in stunted children $(2.9 \pm 0.6 \mathrm{~kg}$ vs $3.2 \pm 0.5 \mathrm{~kg}, \mathrm{p}<0.05)$.

Dietary intakes of stunted and non-stunted children are provided in Table 2 . We found no significant difference in total energy intake as well as macro- and micronutrients intake between stunted and non-stunted children. However, stunted kids had slightly lower intakes of calcium compared to their non-stunted counterparts $(\mathrm{p}=0.06)$. Dietary intakes of dairy products, 


\begin{tabular}{|c|c|c|c|}
\hline \multirow{2}{*}{ Dietary intake } & \multicolumn{2}{|c|}{ Mean \pm SD } & \multirow{2}{*}{$\mathrm{p}$ value } \\
\hline & Cases $(n=86)$ & Controls $(\mathrm{n}=308)$ & \\
\hline \multicolumn{4}{|c|}{ Foods and food groups (g/day) } \\
\hline Bread & $72 \pm 60$ & $87 \pm 64$ & 0.05 \\
\hline Other cereals & $12 \pm 35$ & $16 \pm 41$ & 0.39 \\
\hline Legumes & $43 \pm 71$ & $31 \pm 47$ & 0.14 \\
\hline Potato & $20 \pm 28$ & $23 \pm 36$ & 0.52 \\
\hline Leafy vegetables & $41 \pm 100$ & $32 \pm 48$ & 0.4 \\
\hline Other vegetables & $121 \pm 120$ & $123 \pm 116$ & 0.92 \\
\hline Fruits & $339 \pm 287$ & $343 \pm 316$ & 0.91 \\
\hline Red meats & $56 \pm 88$ & $49 \pm 68$ & 0.50 \\
\hline Poultry & $25 \pm 40$ & $35 \pm 43$ & 0.05 \\
\hline Fish & $14 \pm 49$ & $9 \pm 29$ & 0.33 \\
\hline Visceral meats & $0.2 \pm 2$ & $1 \pm 8$ & 0.06 \\
\hline Eggs & $23 \pm 30$ & $24 \pm 30$ & 0.93 \\
\hline Dairy products & $308 \pm 167$ & $383 \pm 232$ & $<0.05$ \\
\hline Fat and oil & $38 \pm 29$ & $31 \pm 22$ & 0.04 \\
\hline Sugars & $21 \pm 14$ & $22 \pm 20$ & 0.44 \\
\hline Sweets and desserts & $52 \pm 51$ & $63 \pm 58$ & 0.09 \\
\hline Nuts & $8 \pm 17$ & $11 \pm 23$ & 0.13 \\
\hline Dried fruits & $3 \pm 9$ & $7 \pm 26$ & 0.01 \\
\hline Drinks & $238 \pm 198$ & $243 \pm 178$ & 0.84 \\
\hline Flavours & $5 \pm 15$ & $6 \pm 17$ & 0.48 \\
\hline Fast foods & $202 \pm 127$ & $201 \pm 113$ & 0.91 \\
\hline Others & $17 \pm 29$ & $20 \pm 30$ & 0.51 \\
\hline \multicolumn{4}{|l|}{ Nutrients } \\
\hline Energy (kcal/day) & $2104 \pm 858$ & $2178 \pm 77$ & 0.46 \\
\hline Protein (g/day) & $75 \pm 37.6$ & $79 \pm 35$ & 0.32 \\
\hline Fat (g/day) & $77 \pm 35$ & $75 \pm 30$ & 0.67 \\
\hline Carbohydrate (g/day) & $297 \pm 137$ & $317.4 \pm 131$ & 0.22 \\
\hline Calcium (mg/day) & $930 \pm 457$ & $1034 \pm 437$ & 0.06 \\
\hline Iron (mg/day) & $26 \pm 20$ & $26 \pm 19$ & 0.79 \\
\hline Zinc (mg/day) & $10 \pm 6$ & $11 \pm 5$ & 0.26 \\
\hline Vitamin A (mcg/day) & $690 \pm 815$ & $671 \pm 668$ & 0.37 \\
\hline Vitamin C (mg/day) & $110 \pm 122$ & $106 \pm 86$ & 0.30 \\
\hline
\end{tabular}

dried fruits, and nuts were lower but fat and oil consumption was higher among stunted children compared to the non-stunted group (Table $3)$. The difference in the consumption of bread, poultry, visceral meats as well as sweets and desserts between cases and controls was nearly significant.

Factor loadings of foods and food groups in major dietary patterns are presented in Table 3 . Three dietary patterns were identified: 'traditional dietary pattern' that was high in bread, potato, fats, eggs, flavours, vegetables other than leafy vegetables, sugar, drinks, and fast foods; 'mixed dietary pattern' that was dominated by leafy vegetables, fast foods, nuts, fats, cereals other than bread, fruits, legumes, visceral meats, sugar, eggs, and other vegetables; and 'carbohydrate-protein dietary pattern' that was greatly dominated by sweets and desserts, poultry, dairy, fruits, legumes, and visceral meats. On the whole, these dietary patterns explained $23.1 \%$ of the whole variance. 


\begin{tabular}{|lccc|}
\hline \multicolumn{4}{l}{ Table 3. Factor loadings of food groups in major dietary patterns ${ }^{1}$} \\
Food group & \multicolumn{3}{c|}{ Major dietary patterns } \\
\cline { 2 - 4 } & Traditional & Mixed & $\begin{array}{c}\text { Carbohydrate- } \\
\text { protein }\end{array}$ \\
\hline Bread & 0.654 & - & - \\
Potato & 0.556 & - & - \\
Fat and oil & 0.520 & - & - \\
Eggs & 0.498 & - & - \\
Flavours & 0.451 & - & - \\
Sugar & 0.300 & - & - \\
Drinks & 0.264 & - & - \\
Leafy vegetables & - & 0.696 & - \\
Other vegetables & 0.409 & - & - \\
Fast foods & - & 0.567 & - \\
Nuts & - & 0.392 & - \\
Other cereals & - & 0.323 & - \\
Legumes & - & 0.296 & - \\
Visceral meats & - & 0.289 & 0.583 \\
Sweets and desserts & - & - & 0.472 \\
Poultry & - & - & 0.462 \\
Dairy products & - & - & 0.397 \\
Fruits & - & - & 0.343 \\
Others & - & - & - \\
Red meats & - & - & - \\
Fish & - & - & - \\
Dried fruits & - & -9 & \\
Percentage of variance explained & & - & - \\
\hline${ }^{1}$ Factor loadings of less than 0.2 have been & omitted for simplicity & & - \\
\hline
\end{tabular}

Characteristics of the study participants across quartiles of major dietary patterns are shown in Table 4. Mean age, birthweight, and family-size were not significantly different across quartiles of dietary pattern scores. Individuals in the highest quartile of different major dietary patterns were not significantly different in terms of parental education and prevalence of stunting compared to those in the lowest quartile.

Odds ratios for stunting across quartiles of dietary patterns are provided in Table 5. We found no significant associations between 'traditional' and 'mixed' dietary patterns and stunting either before or after adjustment for potential confounders. Individuals in the third quartile of 'carbohydrate-protein' dietary pattern were less likely to be stunted compared to those in the lowest quartile (OR: 0.4, 95\% CI 0.18-0.88). The associations strengthened after further controlling for potential confounders and total energy intake (OR: 0.31, 95\% CI 0.13-0.78).

\section{DISCUSSION}

We found a significant protective association between adherence to 'carbohydrate-protein' pattern and stunting among the first grade students in Tehran. This association remained significant even after taking potential confounders into account. Overall, no significant associations were observed between 'traditional' and 'mixed' dietary patterns and stunting in this population. To the best of our knowledge, this study is the first examining the association between major dietary patterns and stunting.

Although stunting is still highly prevalent in underdeveloped and developing countries, few studies have assessed the role of whole diet in its aetiology. Earlier studies on dietary determinants of stunting have mostly focused on nutrients (19). Findings from such studies have indicated that deficiency of zinc, vitamin A, and iron as well as inadequate intake of protein and energy is the 


\begin{tabular}{|c|c|c|c|c|c|c|c|c|c|}
\hline \multirow[t]{2}{*}{ Characteristics } & \multicolumn{2}{|c|}{$\begin{array}{c}\text { Traditional } \\
\text { pattern's score }\end{array}$} & \multirow[t]{2}{*}{$\mathrm{p}$} & \multicolumn{2}{|c|}{$\begin{array}{l}\text { Mixed pat- } \\
\text { tern's scores }\end{array}$} & \multirow[t]{2}{*}{$\mathrm{p}$} & \multicolumn{2}{|c|}{$\begin{array}{l}\text { Carbohy- } \\
\text { drate-protein } \\
\text { pattern's score }\end{array}$} & \multirow[t]{2}{*}{$\mathrm{p}$} \\
\hline & Q1 & Q4 & & Q1 & Q4 & & Q1 & Q4 & \\
\hline Age (months) & $82 \pm 4$ & $82 \pm 4$ & 0.47 & $82 \pm 4$ & $83 \pm 4$ & 0.42 & $83 \pm 4$ & $82 \pm 4$ & 0.58 \\
\hline Girls (\%) & 71 & 58 & 0.15 & 55 & 67 & 0.28 & 67 & 57 & 0.44 \\
\hline $\begin{array}{l}\text { Mother's age at } \\
\text { delivery (years) }\end{array}$ & $26 \pm 5$ & $27 \pm 5$ & 0.26 & $27 \pm 5$ & $26 \pm 5$ & 0.59 & $28 \pm 6$ & $27 \pm 4$ & 0.23 \\
\hline Birthweight (g) & $3 \pm 1$ & $3 \pm 1$ & 0.51 & $3 \pm 1$ & $3 \pm 1$ & 0.73 & $3 \pm 1$ & $3 \pm 1$ & 0.65 \\
\hline Family-size & $4 \pm 1$ & $4 \pm 1$ & 0.56 & $4 \pm 1$ & $4 \pm 1$ & 0.55 & $4 \pm 1$ & $4 \pm 1$ & 0.43 \\
\hline Mother's education & & & 0.40 & & & 0.41 & & & 0.17 \\
\hline No education & 44 & 0 & & 22 & 44 & & 0 & 33 & \\
\hline Primary & 23 & 35 & & 16 & 39 & & 26 & 29 & \\
\hline $\begin{array}{l}\text { Secondary and un- } \\
\text { der diploma }\end{array}$ & 23 & 26 & & 29 & 20 & & 30 & 26 & \\
\hline $\begin{array}{l}\text { Diploma and } \\
\text { university }\end{array}$ & 55 & 44 & & 56 & 51 & & 33 & 52 & \\
\hline Fathers' education & & & 0.75 & & & 0.54 & & & 0.94 \\
\hline No education & 40 & 20 & & 20 & 20 & & 0 & 40 & \\
\hline Primary & 23 & 37 & & 27 & 33 & & 23 & 30 & \\
\hline $\begin{array}{l}\text { Secondary and un- } \\
\text { der diploma }\end{array}$ & 23 & 25 & & 29 & 24 & & 26 & 25 & \\
\hline $\begin{array}{l}\text { Diploma and } \\
\text { university }\end{array}$ & 47 & 45 & & 48 & 59 & & 51 & 48 & \\
\hline Stunting (\%) & 16 & 25 & 0.14 & 22 & 25 & 0.11 & 20.2 & 27 & 0.32 \\
\hline
\end{tabular}

Table 5. Multivariate-adjusted odds ratios and 95\% confidence intervals for stunting across quartiles of dietary pattern scores ${ }^{1}$

\begin{tabular}{|lcccc|}
\hline \multirow{2}{*}{ Dietary pattern } & \multicolumn{4}{c}{ Quartiles of dietary pattern's scores } \\
\cline { 2 - 5 } & 1 (Lowest) & 2 & 3 & 4 (Highest) \\
\hline Traditional dietary pattern & & & & \\
$\quad$ Crude & 1.00 & $0.69(0.35-1.36)$ & $0.73(0.37-1.44)$ & $0.65(0.33-1.30)$ \\
$\quad$ Model 1 & 1.00 & $0.69(0.35-1.36)$ & $0.74(0.37-1.45)$ & $0.65(0.33-1.30)$ \\
$\quad$ Model 2 & 1.00 & $0.77(0.36-1.65)$ & $0.72(0.33-1.54)$ & $0.79(0.37-1.67)$ \\
$\quad$ Model 3 & 1.00 & $0.79(0.36-1.70)$ & $0.75(0.33-1.71)$ & $0.87(0.34-2.23)$ \\
Mixed dietary pattern & & & & \\
$\quad$ Crude & 1.00 & $1.05(0.53-2.10)$ & $1.11(0.56-2.21)$ & $0.94(0.46-1.89)$ \\
$\quad$ Model 1 & 1.00 & $1.05(0.53-2.11)$ & $1.12(0.56-2.24)$ & $0.95(0.46-1.92)$ \\
$\quad$ Model 2 & 1.00 & $1.18(0.54-2.57)$ & $1.45(0.66-3.17)$ & $0.92(0.41-2.04)$ \\
$\quad$ Model 3 & 1.00 & $1.18(0.54-2.57)$ & $1.46(0.67-3.20)$ & $0.96(0.42-2.19)$ \\
Carbohydrate-protein dietary pattern & & & & \\
$\quad$ Crude & 1.00 & $1.42(0.75-2.70)$ & $0.40(0.18-0.88)^{*}$ & $0.73(0.36-1.46)$ \\
$\quad$ Model 1 & 1.00 & $1.43(0.75-2.71)$ & $0.40(0.18-0.89)^{*}$ & $0.73(0.36-1.46)$ \\
$\quad$ Model 2 & 1.00 & $1.53(0.74-3.19)$ & $0.31(0.13-0.77)^{*}$ & $0.93(0.42-2.06)$ \\
$\quad$ Model 3 & 1.00 & $1.54(0.74-3.20)$ & $0.31(0.13-0.78)^{*}$ & $0.96(0.42-2.18)$ \\
\hline Model 1: Adjusted for age and sex; Model 2: Additionally adjusted for mother's age, parental education, \\
birthweight, duration of breastfeeding, and family-size; Model 3: Further adjusted for total energy intake \\
\hline
\end{tabular}


most important nutritional cause of stunting $(5,11-13,20)$. In the current study, we found no significant differences in dietary intakes of energy and other nutrients, including calcium by comparing stunted and non-stunted children. Due to the age difference and the use of different sets of diets and environments, our results are not directly comparable with those of earlier studies. The discrepant findings might be explained by the different study designs. In terms of foods and food groups intake, we found that stunted children had significantly lower intake of 'dairy products' and 'nuts and dried fruits' and slightly higher intake of 'fats'. Based on these findings, it seems that the diet quality differs between cases and controls (21-24). Calcium has been mainly provided by consumption of milk and dairy foods in the control group and by consumption of foods from other dietary sources, like green leafy vegetables and legumes, in case group. Besides, calcium, milk, and dairy products contain other necessary nutrients, like protein, for promoting growth in height. Therefore, it can be concluded that not only the amount of total calcium intake but also its dietary sources containing protein contents might affect height. Ibrahim and colleagues in Egypt made similar conclusions that deficiency of several nutrients, including proteins, is seen in stunted children, and the combined effect of these deficiencies might have a role in the retardation of growth in height (5). To detect the effect of this combined effect, the 'dietary pattern' approach might be more relevant to dietary aetiology of stunting than that of nutrients (14).

The dietary pattern approach that includes food behaviours of individuals may provide greater information on nutritional aetiology of stunting. Using such a multivariate approach would overcome the problems of collinearity among nutrients, unknown dietary confounders as well as interactions between foods and nutrients. In addition, based on this holistic approach, dietary interventions will be easier and more thorough $(16,25)$.

In the current study, we identified three major dietary patterns, among those, the one with greater amounts of carbohydrate and protein was inversely related to stunting, even after statistical controlling for potential confounders. We didn't find any association between dietary patterns and stunting to compare our findings. However, our results are in line with previous studies, indicating that adequate intake of proteins is required for normal growth. We did not find any association between 'tradition$\mathrm{al}^{\prime}$ and 'mixed' dietary patterns and stunting. Exis- tence of healthy and unhealthy foods together in these dietary patterns might be the reason for lack of association. On the whole, results of our dietary pattern analysis are in the same direction with earlier studies on the significant difference in dairy consumption between stunted and non-stunted children. As stunting is an indicator of long-term malnutrition, monitoring the growth and nutritional status of children since birth should be considered to prevent stunting and its adverse consequences.

\section{Strengths and Limitations}

Several limitations must be considered in the interpretation of our findings. First, the case-control design of this study did not allow us to infer causality. Therefore, the exact association between major dietary patterns and stunting must be confirmed in prospective studies. It must, however, be kept in mind that appropriate analysis of case-control data represent a valuable initial step in identifying diet-disease relations. Moreover prospective cohort studies have their own limitations. Second is the reliance on two days of dietary recalls as a measure of usual dietary intake. The 24-hour recall method is susceptible to recall bias, both for identification of foods eaten and for quantification of portion-sizes. Collecting dietary data by highly-trained interviewers in this study reduce this type of error. Although recalling two days cannot cover all day-to-day variations in dietary intake, using non-consecutive days extends their coverage. Furthermore, various amount estimation tools, including common sizes of mugs, spoons and glasses were used in collecting more accurate data. The 24-hour dietary recall method is the most commonly-used method for dietary surveys. As this method is based on actual intake, it could be used in estimating absolute rather than relative intake of nutrients. This method is completely open-ended, so it can accommodate any food or food combination reported by the subject. This could not be obtainable, using a limited number of food-items in a structured questionnaire. Recalls are specifically useful for estimating dietary intakes of culturally-diverse populations representing a wide range of foods and eating habits. In addition, other epidemiologic studies, such as the Ten State Nutrition Survey, NHANES I, and the Multiple Risk Factor Intervention Trial, have also used the recall method for gathering dietary data. Collecting dietary data for two days could provide more accurate estimates of dietary intake compared to just for one day. The validity of data provided by this method has been reported previously, and it 
has been shown that estimates obtained from recalls are comparable to those obtained with more precise methods, such as dietary records (26). However, as with all dietary assessment tools, the existence of recall bias, under- and over-reporting of dietary intakes as well as lack of coverage of seasonal variation by this method cannot be excluded. Collecting dietary data by highly-trained interviewers in this study reduced this type of error. Although recalling two days cannot cover all day-to-day variations in dietary intake, using non-consecutive days or consecutive 7 days extends their coverage. Finally, stunting is a heterogeneous multi-factorial disorder and besides dietary factors, other variables, such as hereditary factors and metabolic conditions must be considered.

\section{Conclusions}

We found that adherence to dietary patterns high in protein (e.g. dairy, legumes, and meat products) and carbohydrates (e.g. fruits, sweets, and desserts) might be associated with reduced odds of being stunted among children. Further studies are required to confirm our findings.

\section{ACKNOWLEDGEMENTS}

The authors would like to appreciate the Research Council of National Nutrition and Food Technology Research Institute for their financial support. The supports from school teachers, principal, students, and their parents are also highly appreciated. We also thank Seyedeh Marjan Khalafi and Seyed Mohammad Hosseini for their help.

\section{REFERENCES}

1. World Health Organization. Physical status: the use and interpretation of anthropometry; report of a WHO expert committee Geneva: World Health Organization, 1995. 452 p. (WHO technical report series; 854).

2. United Nations Administrative Committee on Coordination, Sub-Committee on Nutrition, International Food Policy Research Institute. Nutrition throughout the life cycle: 4th report on the world nutrition situation. Geneva: United Nations Administrative Committee on Coordination, Sub-Committee on Nutrition, 2000. $140 \mathrm{p}$.

3. de Onis M, Frongillo EA, Blössner M. Is malnutrition declining? An analysis of changes in levels of child malnutrition since 1980. Bull World Health Organ 2000;78:1222-33.

4. Sheikholeslam R, Naghavi M, Abdollahi Z, Zarati M, Vaseghi S, Sadeghi-Ghotbabadi F et al. Current status and trends in the 10-years indices of malnutrition in children under 5 years. Iran J Epidemiol 2000;4:21-8 [Farsi].

5. Ibrahim SA, Abd el-Maksoud A, Nassar MF. Nutritional stunting in Egypt: which nutrient is responsible? East Mediterr Health J 2002;8:272-80.

6. Gibson RS, Vanderkooy PD, MacDonald AC, Goldman A, Ryan BA, Berry M. A growth-limiting, mild zinc-deficiency syndrome in some southern Ontario boys with low height percentiles. Am J Clin Nutr 1989;49:1266-73.

7. Semba RD, de Pee S, Sun K, Sari M, Akhter N, Bloem MW. Effect of parental formal education on risk of child stunting in Indonesia and Bangladesh: a crosssectional study. Lancet 2008;371:322-8.

8. Gibson RS, Ferguson EL. Nutrition intervention strategies to combat zinc deficiency in developing countries. Nutr Res Rev 1998;11:115-31.

9. Ghassemi H, Harrison G, Mohammad K. An accelerated nutrition transition in Iran. Public Health Nutr 2002;5:149-55.

10. Kanao BJ, Abu-Nada OS, Zabut BM. Nutritional status correlated with sociodemographic and economic factors among preparatory school-aged children in the Gaza Strip. J Public Health 2009;17:113-9.

11. Rosado JL, López P, Muñoz E, Martinez H, Allen LH. Zinc supplementation reduced morbidity, but neither zinc nor iron supplementation affected growth or body composition of Mexican preschoolers. Am J Clin Nutr 1997;65:13-9.

12. Ninh NX, Thissen JP, Collette L, Gerard G, Khoi HH, Ketelslegers JM. Zinc supplementation increases growth and circulating insulin-like growth factor I (IGF-I) in growth-retarded Vietnamese children. Am J Clin Nutr 1996;63:514-9.

13. Kiliç I, Ozalp I, Coŝkun T, Tokatli A, Emre S, Saldamli et al. The effect of zinc-supplemented bread consumption on school children with asymptomatic zinc deficiency. J Pediatr Gastroenterol Nutr 1998;26:167-71.

14. Esmaillzadeh A, Azadbakht L. Major dietary patterns in relation to general obesity and central adiposity among Iranian women. J Nutr 2008;138:358-63.

15. Jacobs DR, Jr., Steffen LM. Nutrients, foods, and dietary patterns as exposures in research: a framework for food synergy. Am J Clin Nutr 2003;78(Suppl 3):508S-13S.

16. Esmaillzadeh A, Azadbakht L. Food intake patterns may explain the high prevalence of cardiovascular risk factors among Iranian women. $J$ Nutr 2008;138:1469-75.

17. Esmaillzadeh A, Kimiagar M, Mehrabi Y, Azadbakht L, Hu FB, Willett WC. Dietary patterns and markers 
of systemic inflammation among Iranian women. $J$ Nutr 2007;137:992-8.

18. Azadbakht L, Esmaillzadeh A. Dietary patterns and attention deficit hyperactivity disorder among Iranian children. Nutrition 2012;28:242-9.

19. Gibson RS, Manger MS, Krittaphol W, Pongcharoen $\mathrm{T}$, Gowachirapant S, Bailey KB et al. Does zinc deficiency play a role in stunting among primary school children in NE Thailand? Br J Nutr 2007;97:167-75.

20. Frongillo EA, Jr., de Onis M, Hanson KM. Socioeconomic and demographic factors are associated with worldwide patterns of stunting and wasting of children. J Nutr 1997;127:2302-9.

21. Beyer PL. Digestion, absorption, transport, and excretion of nutrients. In: Mahan KL, Escott-Stump S. Krause's food and nutrition therapy. 12th ed. St. Louis: Elsevier Saunders, 2008:2-18.

22. Gallagher ML. The nutrients and their metabolism.
In: Mahan KL, Escott-Stump S. Krause's food and nutrition therapy. 12the ed. St. Louis: Elsevier Saunders, 2008:32-128.

23. Neumann CG, Bwibo NO, Murphy SP, Sigman M, Whaley S, Allen LH et al. Animal source foods improve dietary quality, micronutrient status, growth and cognitive function in Kenyan school children: background, study design and baseline findings. $J$ Nutr 2003;133(Suppl 2):3941S-9S.

24. Prentice A, Schoenmakers I, Laskey MA, de Bono S, Ginty F, Goldberg GR. Nutrition and bone growth and development. Proc Nutr Soc 2006;65:348-60.

25. Azadbakht L, Surkan PJ, Esmaillzadeh A, Willett WC. The dietary approaches to stop hypertension eating plan affects C-reactive protein, coagulation abnormalities, and hepatic function tests among type 2 diabetic patients. J Nutr 2011;141:1083-8.

26. Willett W. Nutritional epidemiology. 2nd ed. V. 30. New York, NY: Oxford University Press,1998. 514 p. 